\title{
1 Inbreeding may affect phenotypic traits in an Italian population of
}

2 Basset Hound dogs

3

4 Francesca Cecchi · Giovanna Carlini · Lorella Giuliotti · Claudia Russo

5

6 F. Cecchi · L. Giuliotti · C. Russo

7 Department of Veterinary Science, University of Pisa, Viale delle Piagge 2, 56124 Pisa Italy

$8 \quad$ "Corresponding author: F. Cecchi

9 email: francesca.cecchi@unipi.it

10

11 L. Giuliotti

12 email: lorella.giuliotti@unipi.it

13

14

15 C. Russo

16 email: claudia.russo@unipi.it

17

18

19 G. Carlini

20 Professional licensed breeder registered with the ENCI-FCI, Firenze, Italy

21 giovannacarlini@alice.it 


\section{Inbreeding may affect phenotypic traits in an Italian population of 24 Basset Hound dogs}

Abstract The influence of inbreeding depression on phenotypic traits of a Basset Hound dog Italian population was evaluated. Moreover this paper reports the first results of a survey on morphological traits and analyse the genetic variability of the population using genealogical information. The following traits were studied: height at withers, height of chest, depth of chest, body length, length at rump, ischiatic width of rump, circumference of chest, circumference of cannon, length of ear, and length of nose. The inbreeding coefficient (F) of each dog was computed by genealogical data. Traits were taken from 75 adult (mean age $2.17 \pm 1.545$ years) dogs (36 males and 39 females) belonging to 19 different Italian farms. A linear regression of each trait on inbreeding coefficient was used to estimate inbreeding depression. ANOVA was used to test the differences in morphological traits between the sexes, among breeders and among animals with different F level. Despite the good level of genetic variability and the low coefficients of inbreeding observed in the population, a significant weakly effect of inbreeding on the depth of chest was observed. In addition, the present study revealed no significant differences in morphological traits between sexes and among farms.

Keywords Basset Hound dog $\cdot$ Pedigree analysis $\cdot$ Morphological traits $\cdot$ Inbreeding depression

\section{Introduction}

The Basset Hound is a hunting dog, belongs to Group 6 (Segugi e cani per pista di sangue) of the ENCI (Ente Nazionale Cinofilia Italiana) and over 400 puppies are registered every year. Currently in Italy there are 32 official breeders, who breed dogs of American and British bloodlines. Recently Swedish and Dutch lines were also introduced. The breed standard shows rather accurate morphological and behavioural characteristics, although in this breed there are many variables for the height, for the colour of the coat and for the deportment. Basset Hound dog is also used as a model in studies on human hereditary diseases and their gene therapy (Switonski, 2012); in Italy is frequently used for pet therapy (Tomezzoli, 2015). 
51 In the selection the inbreeding is used as a mating method because it allows to fix the 52 characteristics and traits of the best representatives of a breed. However this mating method can lead to high rates of inbreeding with disadvantageous phenomena: in fact, inbreeding can increase genetic diseases (Ubbink et al. 1992), mortality of puppies (Van der Beek et al. 1999) and can cause inbreeding depression (Ubbink et al. 1998, Ólafsdóttir and Kristjánsson 2008). This phenomenon is often associated with fitness reduction (Keller and Waller 2002; Brzeski et al. 2014, Cecchi et al. 2016a) and can also lead to a decrease in selection response for economic traits in the livestock species (Khan et al. 2007, Gonzalez-Recio et al. 2007, Hossein-Zadeh 2012, Malhado et al. 2013, Niknafs et al. 2013, Silió et al. 2012, Mokhtari et al. 2014). The knowledge of the influence of inbreeding on reproductive traits and on the manifestation of specific diseases is crucial for breeders and veterinaries: over 1000 inherited conditions have been reported in dogs (Leroy, 2011) and veterinarians can contribute to the solution of the problem of hereditary disorders in dogs by diagnosing these diseases and helping breeders in the mating management. A better management of the existing genetic variability should constitute an important concern for clubs and breeders (Nicholas et al. 2011). Moreover, it is well known that dog breeders choose animals on the basis of standard characteristics and the beauty of a breed is often equivalent to the functionality and also to the health of an animal. For example the primary function of a Basset Hound is hunting and dogs must follow traces in ravines, brambles and scrubs. So his skin should not be a hindrance to movement and should not be excessive to be entangled and injured. The ears must be long in order to capture the smells of the ground but not too long, thus risking becoming an obstacle to the movement. Considering the health aspect of the animal dogs with excessive skin can more easily meet dermatitis or too much loose skin that falls on the forehead, inevitably leads to the formation of entropion and a laxity of the lower palpebral fissure makes the eye too exposed to atmospheric agents and predisposed to ulcers and conjunctivitis (Società Basset Hound Italiana, 2011). For all these reasons the purposes of the present study were to explore the effects of inbreeding on morphological traits in order to estimate the magnitude of changes associated with an increase in inbreeding and to analyse the genetic variability and morphological traits of a Basset Hound population. 
2 Materials and methods

The research was carried out on 19 different Basset Hounds dog Italian farms (most of these had 1-3 dogs and/or one sex). Genealogical and morphological data of 75 adult (mean age $2.17 \pm 1.545$ years $)$ dogs ( 36 males and 39 females) were monitored. For each male and female body measurements were carried out using a Lydtin stick and tape measure; dogs were put on a flat floor and held by the respective owners (Cecchi et al. 2015). The ten body measurements obtained were: height at withers (WH), height of chest (ChH), depth of chest (ChD), body length (BL), length at rump (RL), ischiatic width of rump (RIsW), circumference of chest (ChC), circumference of cannon (CaC), length of ear (EL), and length of nose (NL).

Concerning genealogical data the number of inbred dogs and the inbreeding coefficient and the average numerator relationships of each dog were obtained using CFC software (Sargolzaei et al. 2006). A linear regression was used do predict each morphological trait based on inbreeding coefficient to estimate inbreeding depression. Values were considered statistically significant for $\mathrm{P}<0.05$ (Confidence Interval 95\%). Solutions were given per $1 \%$ increase of inbreeding.

96 For the analysis of the genetic variability of the population all measured dogs constitutes the

97 Reference Population (RP), while the complete genealogy of the RP constitutes the whole 98 population (WP), containing all founders, ancestors and their offspring; the base of population

99 (BP) was defined as individuals with one or both unknown parents. The distribution of inbreeding 100 in the whole population was analysed. Different levels of inbreeding were identified and dogs 101 were divided into nine classes according to its own F level: class 1 including non-inbred animals $102(\mathrm{~F}=0)$; all the other eight classes include inbred animals (class 2: dogs with an $\mathrm{F}$ value between 1030 and 0.05 ; class 3: dogs with an F value between 0.05 and 0.10 ; class 4 : dogs with an $\mathrm{F}$ value 104 between 0.10 and 0.15 ; class 5: dogs with an F value between 0.15 and 0.20 ; class 6: dogs with 105 an F value between 0.20 and 0.25 ; class 7 : dogs with an F value between 0.25 and 0.30 ; class 8: 
106 dogs with an F value between 0.30 and 0.35 . A multivariate analysis of variance was used to test

107 the effect of sex, inbreeding level and farm on each morphological trait, including dog age at the

108 time of the study as covariate. Three variables were entered as fixed factors: sex in the first model,

109 different inbreeding class levels and sex in the second model and farm and in the third model. In

110 this last one model we considered only the farms $(n=5)$ who breed more than 5 dogs $(27$ animals

111 in total, 11 males and 16 females); it was no possible consider sex factor because some of these

112 farms have only females. Morphological data were analysed by SAS-JMP software version 5.0

113 (2002).

114

\section{Results and discussion}

116 Table 1 reports morphological data in males and females. For all traits, between males and

117 females, no statistical significantly differences were observed. These results were also confirmed

118 by the measures of sexual dimorphism (m/f) that ranged from 0.99 for $\mathrm{ChC}$, RIsW and NL to 1.02

119 for $\mathrm{CaC}$. In the breed standard (ENCI), the height at withers is the only parameter for which range

120 is reported: from 33 to $38 \mathrm{~cm}$ (with no differences between males and females). In this research

121 the average withers height was $35.8 \pm 1.57 \mathrm{~cm}$ in females and $36.0 \pm 1.76 \mathrm{~cm}$ in males. These

122 values fall exactly in the expected ranges defined by the current breed standard. Only one male

123 in the sample exceeded the maximum value $(39 \mathrm{~cm})$ while a female had a lower value $(32 \mathrm{~cm})$.

124 The age at measurement did not show significant effects as well as no significant differences in

125 the traits were observed among dogs belonging to different breeders. A few number of study have

126 been performed on the morphological parameters of dog breeds; these studies have been

127 conducted with breed dogs with a very different morphology, such as Spanish water dogs (Barba

128 Capote et al. 1996), Bolognese dogs (Beretti et al. 2008), Lagotto dogs (Vaccari Simonini et al.

129 2007) and Bracco Italiano dogs (Cecchi et al. 2015). Also Jordana et al. (1999) had analysed

130 several morphological and behavioural characters of a series of breeds, including Basset Hound,

131 in order to improve the knowledge of relationships among these breeds. However, scores were

132 assigned to each state of different characteristics in an arbitrary manner and no analytical 
measurements were conducted. In our study 35 dogs out 75 (46.7\%) of the Reference Population

134 were inbred and all had an inbreeding coefficient less than 0.15 (Table 2). Therefore, considering

135 the complete database, 47 dogs were inbred. Of these dogs, 22 dogs $(68.75 \%$ of the inbred)

136 showed an inbreeding value lower than $5 \%$ while only 3 dogs $(9.37 \%$ of the inbred) showed an

137 inbreeding value higher than $20 \%$.

138 A significant regression equation was found for the depth of chest $(\mathrm{ChD}=32.6-0,659 \mathrm{~F})$ with a

$139 \mathrm{R}^{2}{ }_{\mathrm{ADJ}}$ of $13.98 \%$. Dogs' depth of chest decreased $0.659(\mathrm{p}<0.05)$ for each $1 \%$ increase of

140 inbreeding. No statistically significant effects were detected for all other traits. Table 3 reports

141 the morphological differences among animals with various $\mathrm{F}$ levels. The depth of chest was

142 significantly lower in animals with $\mathrm{F}$ values included between $5 \%$ and $10 \%(\mathrm{P}<0.05)$ in

143 comparison to animals with $\mathrm{F}<5 \%$; this effect increased in animals with $\mathrm{F}$ values included

144 between $10 \%$ and $15 \%(\mathrm{P}<0.01)$. A weakly reduction of $\mathrm{ChC}$ due to inbreeding was also

145 observed; this effect was even highlighted by Gandini et al. (1992) in Haflingers horse breed. The

146 effects of inbreeding on morphological traits have been studied in other horse breeds: Gomez et

147 al. (2009) found significant inbreeding depression for several biometrical measurements in

148 Spanish Purebred horses. On the other hand, Curik et al. (2003) in Lipizzan horse and

149 Sierszchulski et al. (2005) in Arabian horse found no effect of inbreeding on morphological traits.

150 Wolc and Balińska (2010) reported that inbreeding was associated with a decrease in whither

151 height in Sieraków horse, but not in Dobrzyniewo and in Kobylniki horse. To our knowledge,

152 there is only the paper by Cecchi et al. (2015) on the effect of inbreeding on traits in Bracco

153 Italiano dog showing that no inbreeding depression, computed using the same model, was

154 observed on the conformation traits. It is well known that different breeds and populations, as

155 well as different traits, vary in their response to inbreeding: some populations may show a very

156 pronounced effect of increased inbreeding for a trait, whereas other populations may not

157 demonstrate much of an effect. For example, Jansson and Laikre (2014) did not find any

158 correlation between inbreeding and health in 26 dog breeds in Sweden. As reported by Barczak

159 et al. (2009), in a given population, "bad" and "good" inbreeding effects are mixed. Furthermore, 
160 the degree of inbreeding depression in a population depends on the extent of inbreeding, the

161 original frequency of deleterious recessives, the environment, and inbreeding depression may be

162 greater under more stressful conditions (Marr et al. 2006).

163 Table 4 summarizes the main genealogical parameters computed by CFC. Analysis of the 164 pedigrees of the 75 studied dogs (RP) showed that the complete database resulted in 333 dogs 165 (WP), distributed in ten traced generations. Sires and dams in total were 125 and 147, 166 respectively, with a ratio dams-sires of 1.18. This value was smaller than reported on Bracco 167 Italiano dog breed (1.63) (Cecchi et al. 2013) and on Bracco Francese dog breed (1.31) (Cecchi 168 et al. 2016b). Number of animals in the base population (one or both unknown parents: absolute 169 founders $=\mathrm{ft}$ ) was 131 . Average value of inbreeding $(\mathrm{F})$ in the whole population $(\mathrm{WP})$ was $1.1 \%$ 170 while the average value of $\mathrm{F}$ in the reference population (RP) was $3.2 \%$ ( $7.7 \%$ in the inbred). Of 171 the 19 considered farms, 12 had inbred animals with an average $\mathrm{F}$ ranging from 0.1 to $10.7 \%$ 172 (data not shown). Many studies have explored inbreeding in dog breeds, showing different 173 average value of the pedigree coefficient inbreeding both within and amongst breeds, which also 174 varies across countries (Różańska-Zawieja et al. 2013). The results presented in this paper suggest 175 that this population of Basset Hound had a good level of genetic variability. In fact, our results 176 were generally smaller than those reported in many other dog breeds. In particular the average 177 coefficient of inbreeding observed in this Basset Hound population for the RP (3.2\%) was smaller 178 than those reported by Cole et al. (2004) in a population of Labrador Retriever $(\mathrm{F}=22 \%)$ and 179 German Shepherd (26.2\%) guide dogs and by Glażewska (2008) for a small population of Polish 180 Hounds born in the period 1970-2004 (F=26.5\%-37.0\%). Also Voges and Distl (2009) reported 181 value of inbreeding coefficients ranging from about 4.5\% for Bavarian Mountain Hounds to about $1829.5 \%$ for Tyrolean Hounds. The average inbreeding coefficients estimated by Martinez et al 183 (2011) for Cimarrón Uruguayo dog breed, reached about 4-6\% while in a study on breeds raised 184 in France (Leroy et al. 2006) the average coefficient of inbreeding ranged from 3.3\% in 185 Bouledougue Francais to $12.4 \%$ in Barbet breed dog. In an Italian population of Pit Bull Terrier 186 dogs the average coefficient of inbreeding was 3.73\% (Ciampolini et al. 2013), while the average 
187 coefficient of inbreeding in an Italian population of the dog Braque Français type Pyrénées was

$1884.35 \%$ (Cecchi et al. 2016b). In some Italian breeds F value ranged from $2.27 \%$ in Lagotto 189 Romagnolo (Sabbioni et al. 2008), 6.29\% in Bracco Italiano dog breed (Cecchi et al. 2013) to $19010.81 \%$ in Bolognese dog breed (Sabbioni et al. 2007). On the other hand, values of inbreeding 191 smaller than $1 \%$ were reported by Cecchi et al. (2009) in an Italian colony of guide dogs $(0.45 \%$ 192 in German Shepherd dogs, $0.38 \%$ in Labrador dogs and $0.49 \%$ for Golden Retriever dogs) and 193 by Różańska -Zawieja et al. (2013) in the Hovawart dogs (0.26-0.31\%).

\section{Conclusion}

Despite the good level of genetic variability and the low coefficients of inbreeding of this Basset Hound population, our data suggest that inbreeding has effect mainly on the depth of

198 chest starting from the F values between $10 \%$ and $15 \%$. It should be noted that according to the 199 breed standard (ENCI), the chest should be neither narrow nor excessively descended. An 200 inbreeding-related reduction in the depth of chest could thus be advantageous for those animals 201 in which an excessive depth of chest is undesirable to the farmers. In fact, farmers considered this as an unpleased feature because Basset Hound was created to follow traces in ravines, brambles, scrubs and other place impossible to penetrate for other hounds; an excessive chest depth that

204 rubs into the ground, is not the most suitable for hunting and would can cause difficulty in 205 movements.

206 We do not know the effects that $\mathrm{F}$ values greater than $15 \%$ might have on these traits but it would 207 be interesting to extend the sample size considering high inbred animals in order to verify the 208 interesting results. Furthermore, it would be interesting to calculate inbreeding depression on 209 other very important physiological aspects such as the neonatal survival, stress resistance, 210 fertility, reproductive success, longevity, and birth weight.

\section{Disclosure statement}


213 The Authors report that they have no conflicts of interest. The Authors alone are responsible for

214 the content and writing of this article.

215

216 ACKNOWLEDGMENTS

217

This work is supported by grant of University of Pisa (Ateneo - Prof Francesca Cecchi)

\section{References}

219

220

Barba Capote CJ, Herrera Garcia M, Delgado Bermejo JV, Gutiérrez Cabezaz MJ. (1996) Morpho-functional differences in the spanish water dog. Arch Zootec 45:37-43.

Barczak E, Wolc A, Wójtowski J, Ślósarz P, Szwaczkowski T. (2009) Inbreeding and inbreeding depression on body weight in sheep. J Anim Feed Sci 18: 42-50.

Beretti V, Vaccari Simonini F, Soffiantini CS, Sabbioni A. (2008) Morphological characteristics and growth curves of Bolognese dog breed. Proc. 62th SISVET Congress, S. Benedetto del Tronto (AP), 24-26 Settembre 2008, 449-450.

227

Brzeski KE, Rabon DRJ, Chamberlain MJ, Waits LP, Taylor SS. (2014) Inbreeding and inbreeding depression in endangered red wolfes (Canis rufus). Mol Ecol 23:4241-4255.

Cecchi F, Bramante, A, Mazzanti E, Ciampolini R. (2009) A colony of dog guides: analysis of the genetic variability assessed by pedigree data. Ital J Anim Sci 8(Suppl. 2):48-50.

Cecchi F, Paci G, Spaterna A, Ciampolini R. (2013) Genetic variability in Bracco Italiano dog breed assessed by pedigree data. Ital J Anim Sci 12:348-352.

Cecchi F, Paci G, Spaterna A, Ciampolini R. (2015) Morphological traits and inbreeding depression in Bracco Italiano dog breed. Ital J Anim Sci 14:374-377.

Cecchi F, Giacalone G, Paci G. (2016a) Inbreeding depression in Lizard canaries breed estimated by pedigree analysis. Czech J Anim Sci 61:15-21.

Cecchi F, Paci G, Spaterna A, Ragatzu M, Ciampolini R. (2016b) Demographic approach on the study of genetic parameters in the dog Braque Français type Pyrénées Italian population. 
240 Ciampolini R, Cecchi F, Paci G, Policardo C, Spaterna A. (2013) Investigation on the Genetic

241 Variability of the American Pit Bull Terrier dogs belonging to an Italian breeder using

242 Microsatellite Markers and genealogical data. Cytology and Genetics 47:217-221.

243 Cole JB, Franke DE, Leighton EA. (2004) Population Structure of a Colony of Dog Guides. J $244 \quad$ Anim Sci 82:2906-2912.

245 Curik I, Zechner P, Sölkner J, Achmann R, Bodo I, Dovc P, Kavar T, Marti E, Brem G. (2003)

246 Inbreeding, microsatellite heterozygosity, and morphological traits in Lipizzan horses. J

$247 \quad$ Hered 94:125-32.

248 Gandini GC, Bagnato A, Miglior F, Pagnacco G. (1992) Inbreeding in the Italian Haflinger horse.

$249 \quad$ J Anim Breed Genet 109:433-43.

250 Gómez MD, Valera M, Molina A, Gutiérrez JP, Goyache F. (2009) Assessment of inbreeding depression for body measurements in Spanish Purebred (Andalusian) horses. Livest Sci 122: $149-55$

Gonzales-Recio O, Lopez de Maturana E, Gutierrez JP. (2007) Inbreeding depression on female fertility and calvin case in Spanish dairy cattle. J Dairy Sci 90:5744-5752.

Glażewska I. (2008) Genetic diversity in Polish hounds estimated by pedigree analysis. Livest Sci 113:296-301

Hossein-Zadeh NG. (2012) Inbreeding effects on body weight traits of Iranian Moghani sheep. Arch Tierz 55: 171-178.

Jansson M, Laikre L. (2014) Recent breeding history of dog breeds in Sweden: modest rates of inbreeding, extensive loss of genetic diversity and lack of correlation between inbreeding and health. Animal Breeding and Genetics 131:153-162.

Jordana J, Manteca X, Ribo O. (1999) Comparative analysis of morphological and behavioral characters in the domestic dog and their importance in the reconstruction of phylogenetic relationships in canids. Genet Mol Biol 22:49-57.

265 Khan MS, Ali A, Hyder AU, Iqbal AI. (2007) Effect of inbreeding on growth and reproduction traits of Beetal goats. Arch Tierz 50:197-203. 
Keller LF, Waller DM. (2002) Inbreeding effects in wild populations. Trend Ecol Evol 17:230241.

Leroy G, Rognon X, Varlet A, Joffrin C, Verrier E. (2006) Genetic variability in French dog breed assessed by pedigree data. J Anim Breed Genet 123:1-9.

Leroy G. (2011) Genetic diversity, inbreeding and breeding practices in dogs: results from pedigree analyses. Vet J 189:177-182.

Malhado CHM, Malhado ACM, Carneiro PLS, Ramos AA, Carrillo J A, Pala A. (2013) Inbreeding depression on production and reproduction traits of buffaloes from Brazil. Anim Sci J 84:289-295.

Marr AB, Arcese P, Hochachka WM, Reid JM, Keller LF. (2006) Interactive effects of environmental stress and inbreeding on reproductive traits in a wild bird population. J. Anim. Ecology 75:1406-1415

Martinez M, Armstrong E, Gagliardi R, Y Llambi S. (2011) Estudio ógico del perro Cimarrón Urugayo (Pedigree analysis of the canine breed Cimarrón Uruguayo). Archiv de Zoot 60:1327-1330.

Mokhtari MS, Moradi Shahrbabak M, Esmailizadeh AK, Moradi Shahrbabak H, Gutierrez JP. (2014) Pedigree analysis of Iran-Black sheep and inbreeding effectson growth and reproduction traits. Small Rum Res 16:14-0.

Nicholas FW, Crook A, Sargan DR (2011) Internet resources cataloguing inherited disorders in dogs. Vet J 189: 132-135.

Niknafs S, Abdi H, Fatemi SA, Zandi MB, Baneh H. (2013) Genetic Trend and Inbreeding Coefficients Effects for Growth and Reproductive Traits in Mazandaran Indigenous Chicken. J of Biology 3:25-31

Ólafsdóttir GA, Kristjánsson T. (2008) Correlated pedigree and molecular estimates of inbreeding and their ability to detect inbreeding depression in the Icelandic sheepdog, a recently bottlenecked population of domestic dogs. Conserv Gen 9:1639-1641.

Różańska-Zawieja J, Nienartowicz-Zdrojewska A, Mucha M, Sobek Z, Stanisławsk D, Gierdziewicz M, Kania-Gierdziewicz J. (2013) Evaluation of inbreeding and relationship 
coefficients in Hovawart dogs and analysis of trends in coat colour changes. Ann Anim Sci

SAS, J.M.P. (2002) User's Guide, ver. 5.0 SAS Inst. Cary, NC, U.S.A.

Sabbioni A, Beretti V, Vaccari Simonini F. (2007) Parametri demografici, variabilità genetica e struttura della popolazione nella razza canina "Lagotto Romagnolo". Proc. LXI Congr. S.I.S.Vet, Salsomaggiore Terme, Italy, pp 409-410.

Sabbioni A, Beretti V, Vaccari Simonini F. (2008) Parametri demografici, variabilità genetica e struttura della popolazione nella razza canina Bolognese. Proc. LXII Congr. S.I.S.Vet, San

Sargolzaei M, Iwaisaki H, Colleau JJ. (2006) CFC (Contribution, Inbreeding (F), Coancestry, Release 1.0. A software package for pedigree analysis and monitoring genetic diversity. Proc. 8th World Cong. on Genetics Applied on Livestock Production, Belo Horizonte, Brazil, CD-ROM comm. N 27-28.

Silió L, Rodríguez MC, Fernández A, Barrangán C, Benítez R, Óvilo C, Fernández AI. (2012) Measuring inbreeding and inbreeding depression on pig growth from pedigree or SNPderived metrics. J Anim Breed Genet 130:349-360.

Sierszchulski J, Helak M, Wolc A, Szwaczkowski T, Schlote W. (2005) Inbreeding rate and its effect on some conformation traits in Arabian mares. Anim Sci Pap Rep 23:51-9.

Società Basset Hound Italiana (2011) Lo standard ufficiale di razza. (FCI Standard nº 163 del 27 gennaio 2011). www.canitalia.it/club/bassethound/index2.htm

Switonski M. (2014) Dog as a model in studies on human hereditary disease and their gene therapy. Reprod Biol 14:44-50.

317 Tomezzoli A. (2015) Il Basset Hound e la pet therapy. Basset Hound e dintorni. La prima rivista on line dedicata ai nostri Basset, a cura della S.i.Bas (Società Italiana Basset Hound) 3:1416.

Ubbink GJ, Knol BW, Bouw J. (1992) The kinship between homozigosity and the occurrence of specific diseases in Bouvier Belge Des Flandres dogs in Netherlands. Vet Q 14:137-140. 
322 Ubbink GJ, van de Broek HAW, Hazewinkel K, Rothuizen J. (1998) Risk estimates for 323 dichotomous genetic disease traits based on a cohort study of relatedness in purebred dog 324 populations. Vet Rec 142:209-213.

325 Vaccari Simonini F, Beretti V, Sabbioni A. (2007) Morphologic characteristics of "Lagotto 326 Romagnolo" dog breed. Proc. 61th SISVET Congress, Salsomaggiore Terme (PR) 26-29 $327 \quad$ September, 411-412.

328 Van der Beek S, Nielen AL, Schukken YH, Brascamp EW. (1999) Evaluation of genetic, 329 common-litter, and within-litter effects on preweaning mortality in a birth cohort of puppies. $330 \quad$ A J Res 60:1106-1110.

331 Voges S, Distl O. (2009) Inbreeding trends and pedigree analysis of Bavarian mountain hounds, Hanoverian hounds and Tyrolean hounds. J Anim Breed Genet 126:357-365

333 Wolc A, Balińska K. (2010) Inbreeding effects on exterior traits in Polish konik horses. Arch 334 Tierz 53:1-8

335 
336 Table 1 Means, standard deviation (SD) and Sexual Dimorphism for each morphological trait in 337 both males and females

338 Table 2 Distribution of inbreeding coefficients in the WP and in RP

339 Table 3 Mean and standard error (SE) for each morphological trait in dogs subdivided

340 according to different inbreeding class

341 Table 4 Main genealogical parameters computed for dog pedigree

342 


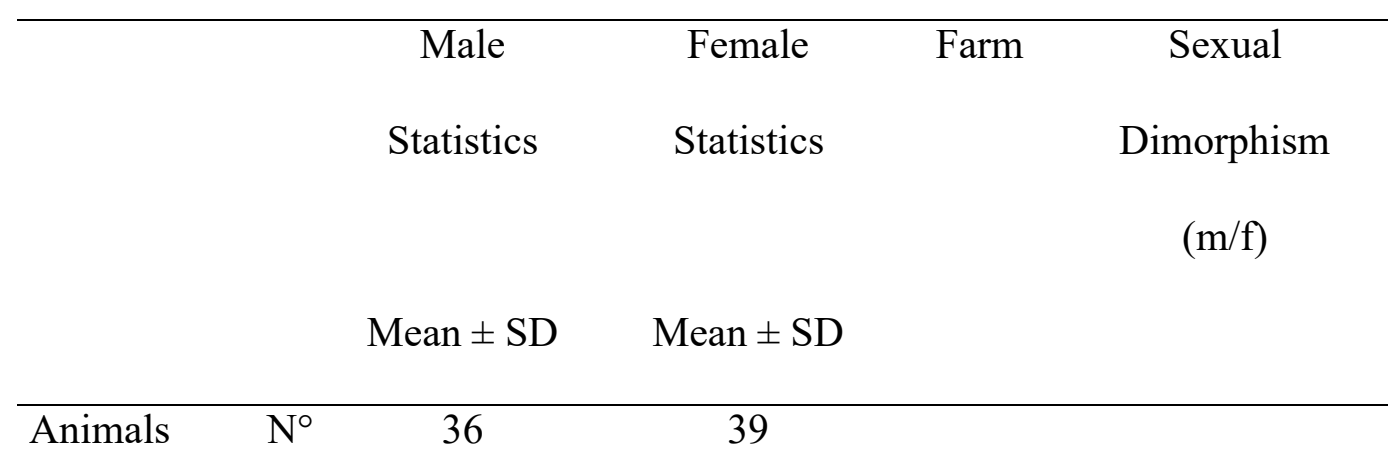

Traits

$\begin{array}{lccccc}\mathrm{WH} & \mathrm{cm} & 36.0 \pm 1.76 & 35.8 \pm 1.57 & \mathrm{~ns} & 1.00 \\ \mathrm{ChC} & \text { “ } & 72.4 \pm 4.85 & 73.28 \pm 3.87 & \mathrm{~ns} & 0.99 \\ \mathrm{CaC} & \text { “ } & 5.6 \pm 1.00 & 5.5 \pm 1.12 & \mathrm{~ns} & 1.02 \\ \mathrm{ChD} & & 32.6 \pm 0.93 & 32.6 \pm 0.90 & \mathrm{~ns} & 1.01 \\ \mathrm{ChH} & \text { “ } & 17.5 \pm 0.38 & 17.3 \pm 0.40 & \mathrm{~ns} & 1.01 \\ \mathrm{BL} & \text { “ } & 58.5 \pm 1.08 & 58.01 \pm 4.90 & \mathrm{~ns} & 1.00 \\ \mathrm{RL} & \text { “ } & 22.8 \pm 0.50 & 22.8 \pm 0.57 & \mathrm{~ns} & 1.00 \\ \mathrm{RIsW} & \text { “ } & 31.5 \pm 1.23 & 31.7 \pm 0.70 & \mathrm{~ns} & 0.99 \\ \mathrm{EL} & \text { “ } & 23.2 \pm 0.63 & 23.1 \pm 0.94 & \mathrm{~ns} & 1.00 \\ \mathrm{NL} & \text { “ } & 10.9 \pm 0.52 & 11.00 \pm 0.55 & \mathrm{~ns} & 0.99\end{array}$

344 WH: height at withers; ChC: circumference of chest; $\mathrm{ChH}$ : height of chest; ChD: depth of Chest;

345 CaC: circumference of cannon; BL: body length; RL: length at rump; RIsW: ischiatic width of

346 rump; EL: length of ear; NL: Nose length. ns: not significant.

347 Significant values for $\mathrm{P} \leq 0.05$.

$348 \mathrm{~m} / \mathrm{f}=$ ratio between mean values of males and females 
$351 \quad$ Table 2

\begin{tabular}{llcc}
\hline Range & & $\mathrm{WP}^{*}$ & $\mathrm{RP}^{* *}$ \\
\hline $0.00<\mathrm{F}<0.05$ & $\mathrm{~N}^{\circ}$ & 22 & 14 \\
$0.05<\mathrm{F}<0.10$ & “ & 6 & 6 \\
$0.10<\mathrm{F}<0.15$ & “ & 16 & 15 \\
$0.15<\mathrm{F}<0.20$ & “ & 0 & 0 \\
$0.20<\mathrm{F}<0.25$ & “ & 2 & 0 \\
$0.25<\mathrm{F}<0.30$ & “ & 0 & 0 \\
$0.30<\mathrm{F}<0.35$ & “ & 1 & 0
\end{tabular}

352 *WP: whole population;

$353 * *$ RP: reference population 


\begin{tabular}{lccccc}
\hline & & $\mathrm{F}=0$ & $0<\mathrm{F} \leq 0.05$ & $0.05<\mathrm{F} \leq 0.10$ & $0.10<\mathrm{F} \leq 0.15$ \\
& & Mean $\pm \mathrm{SE}$ & Mean $\pm \mathrm{SE}$ & Mean $\pm \mathrm{SE}$ & Mean $\pm \mathrm{SE}$ \\
\hline Animals & $\mathrm{N}^{\circ}$ & 40 & 14 & 6 & 15 \\
Traits & & & & & \\
$\mathrm{WH}$ & $\mathrm{cm}$ & $35.90 \pm 0.254$ & $36.22 \pm 0.487$ & $35.72 \pm 0.843$ & $35.71 \pm 0.435$ \\
$\mathrm{ChC}$ & “ & $72.85^{\mathrm{a}} \pm 0.649$ & $71.18^{\mathrm{ab}} \pm 1.243$ & $71.00^{\mathrm{ab}} \pm 1.152$ & $70.65^{\mathrm{b}} \pm 1.111$ \\
$\mathrm{ChH}$ & “ & $17.37 \pm 0.061$ & $17.47 \pm 0.116$ & $17.57 \pm 0.202$ & $17.23 \pm 0.104$ \\
$\mathrm{ChD}$ & & $32.75^{\mathrm{Aa}} \pm 0.133$ & $32.45^{\mathrm{Aa}} \pm 0.255$ & $31.52^{\mathrm{Ab}} \pm 0.441$ & $30.69^{\mathrm{B}} \pm 0.227$ \\
$\mathrm{CaC}$ & “ & $5.51 \pm 0.162$ & $5.52 \pm 0.311$ & $5.92 \pm 0.539$ & $5.48 \pm 0.278$ \\
$\mathrm{BL}$ & “ & $57.99 \pm 0.551$ & $58.48 \pm 1.055$ & $58.25 \pm 1.828$ & $58.85 \pm 0.943$ \\
$\mathrm{RL}$ & “ & $22.77 \pm 0.082$ & $22.90 \pm 0.157$ & $22.72 \pm 0.272$ & $22.72 \pm 0.141$ \\
$\mathrm{RIsW}$ & “ & $31.42 \pm 0.131$ & $31.54 \pm 0.249$ & $31.97 \pm 0.432$ & $31.90 \pm 0.223$ \\
$\mathrm{EL}$ & “ & $23.14 \pm 0.121$ & $23.27 \pm 0.232$ & $23.87 \pm 0.402$ & $23.19 \pm 0.208$ \\
$\mathrm{NL}$ & “ & $10.83 \pm 0.080$ & $10.98 \pm 0.153$ & $11.27 \pm 0.266$ & $11.27 \pm 0.137$
\end{tabular}

355 WH: height at withers; ChC: circumference of chest; ChH: height of chest; ChD: depth of Chest;

$356 \mathrm{CaC}$ : circumference of cannon; BL: body length; RL: length at rump; RIsW: ischiatic width of 357 rump; EL: length of ear; NL: Nose length.

358 Different letters on the same row show significant differences: ${ }^{\mathrm{A}, \mathrm{B}} \mathrm{P} \leq 0.01$; ${ }^{\mathrm{a}, \mathrm{b}} \mathrm{P} \leq 0.05$. 


\begin{tabular}{|c|c|}
\hline & No. \\
\hline Whole population (WP) & 333 \\
\hline & 125 \\
\hline - Sires in total & 147 \\
\hline - Dams in total & \\
\hline Inbreed in the whole population & 47 \\
\hline Average $\mathrm{F}$ in the whole population & 0.011 \\
\hline Average $\mathrm{F}$ in the inbred of the whole population & 0.078 \\
\hline Reference population (RP) & 75 \\
\hline Inbreed in the reference population & 35 \\
\hline Average $\mathrm{F}$ in the reference population & 0.032 \\
\hline Average $\mathrm{F}$ in the inbred of reference population & 0.077 \\
\hline Base population $\left(\right.$ one or two unknown parents $\left.=\mathrm{f}_{\mathrm{t}}\right)(\mathrm{BP})$ & 131 \\
\hline
\end{tabular}

361

362

363 